\title{
Commentary: Virtual fit reality and tailored approach in ventricular assist device implantation
}

\author{
John M. Karamichalis, MD, ${ }^{\mathrm{a}}$ and \\ David N. Campbell, MD ${ }^{b}$
}

Recent technical advances in medicine have made several new tools available to surgeons in the preoperative and intraoperative care of patients for more precise diagnosis, planning, and execution of surgical procedures. The application of 3-dimensional (3D)-printing, computer modeling, highresolution computed tomography $\mathrm{CT}$ scan and reconstruction, 3D echocardiography, and, more recently, virtual reality are examples of these sophisticated technological advances used by surgeons toward a personalized patient approach. ${ }^{1-3}$

Tailoring the surgical approach based on individual patient anatomy using advanced technology may be key to the success of complex congenital heart operations, organ transplantation, and mechanical circulatory support device implantation. Recently, virtual heart transplantation has allowed donor-recipient size matching to be individualized, ${ }^{4}$ expanding the potential donor pool for pediatric heart transplant recipients. This represents a movement away from using generalized assumptions about heart size, chest wall anatomy, and spatial relationships of cardiothoracic structures to determine size match. Furthermore, virtual implantation of the total artificial heart

From the ${ }^{\text {aSection }}$ of Pediatric and Congenital Cardiac Surgery, Division of Cardiac, Thoracic, and Vascular Surgery, New York Presbyterian-Morgan Stanley Children's Hospital, Columbia University Medical Center, New York, NY; and ${ }^{\mathrm{b} D i v i-}$ sion of Congenital Cardiac Surgery, Children's Hospital Colorado, University of Colorado, Aurora, Colo.

Disclosures: The authors reported no conflicts of interest.

The Journal policy requires editors and reviewers to disclose conflicts of interest and to decline handling or reviewing manuscripts for which they may have a conflict of interest. The editors and reviewers of this article have no conflicts of interest.

Received for publication Dec 1, 2020; revisions received Dec 1, 2020; accepted for publication Dec 15, 2020; available ahead of print Dec 25, 2020.

Address for reprints: John M. Karamichalis, MD, Division of Cardiac, Thoracic and Vascular Surgery, New York-Presbyterian/Morgan Stanley Children's HospitalColumbia/Komansky Weill-Cornell, 3959 Broadway, CHN-274, New York, NY 10032 (E-mail: jkaramichalis@yahoo.com).

JTCVS Techniques 2021;6:140-1

2666-2507

Copyright (C) 2020 The Authors. Published by Elsevier Inc. on behalf of The American Association for Thoracic Surgery. This is an open access article under the CC BY-NCND license (http://creativecommons.org/licenses/by-nc-nd/4.0/).

https://doi.org/10.1016/j.xjtc.2020.12.007

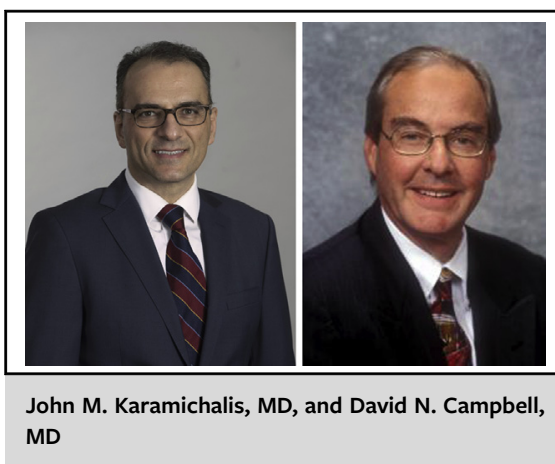

CENTRAL MESSAGE

Tailoring the surgical approach using virtual fit reality of individual patient's morphology may be key in successful implantation of ventricular assist devices outside the standard fit criteria.

(Syncardia) has been shown to expand the eligibility for device placement in patients whose body surface area (BSA) falls outside predefined standard fit criteria for the 70-cc and 50-cc devices. ${ }^{5}$

The article by Davies and colleagues ${ }^{6}$ in this issue of the Journal is a welcome addition to the literature. The authors examined the use of virtual reality simulated implantation from cross-sectional imaging to evaluate intrapericardial placement of the Heartware HVAD and Heartmate3 intrapericardial pumps in children. Tailoring the surgical approach based on individual morphology using this advanced technology appears to be critical for obtaining a successful operative outcome when attempting to implant an adult device in a very small child. By helping surgeons choose the best choice and fit for VAD implantation in pediatric patients, virtual fit testing is yet another advancement to facilitate the implantation of these adult VADs in children and to explore the lower limits of patient size.

Although previous studies have used this methodology, ${ }^{4,5}$ this study is unique in attempting to define measurement criteria based on the apex to mitral valve distance as determined by virtual fit testing as a more accurate approach to device placement than BSA and weight. As the authors state, virtual fit testing allows for more accurate assessment of pump placement, particularly the angle of the inflow cannula toward the atrioventricular valve.

Virtual fit testing is another tool in the armamentarium for individualized precision medicine enabling a personalized 
surgical approach in choosing the best VAD suited to each patient's unique anatomy.

It is important to note that despite the advances afforded by technology in allowing us to be as precise as possible, we are still limited by the dynamic nature of the heart, whose size and shape continuously remodels and readjusts based on the patient's hemodynamic status, especially after implantation of a VAD. Although technology and virtual reality fit may be sophisticated tools aiding the surgeon for a precise individualized patient approach, we could many times be mislead, faulted, or we could underestimate the change of the heart's size and shape that occurs after VAD implantation by the ongoing dynamic remodeling that the heart undergoes that may result in a better fit of the VAD than initially thought.

\section{References}

1. Karamichalis JM, Aguid H, Anastasopulos A, Yacoub M. Surgical relief of left ventricular outflow obstruction in pediatric hypertrophic cardiomyopathy: the need for a tailored approach. J Thorac Cardiovasc Surg. 2018;156:2283-4.

2. Ong CS, Krishnan A, Huang CY, Spevak P, Vricella L, Hibino N, et al. Role of virtual reality in congenital heart disease. Congenit Heart Dis. 2018;13:357-61.

3. Kiraly L. Three-dimensional virtual and printed models improve preoperative planning and promote patient-safety in complex congenital and pediatric cardiac surgery. Orv Hetil. 2019;160:747-55.

4. Szugye NA, Lorts A, Zafar F, Taylor M, Morales DLS, Moore RA. Can virtual heart transplantation via 3-dimensional imaging increase the maximum acceptable donor size? J Heart Lung Transplant. 2019;38:331-3.

5. Moore RA, Lorts A, Madueme PC, Taylor MD, Morales DL. Virtual implantation of the 50-cc SynCardia total artificial heart. J Heart Lung Transplant. 2016;35: 824-7.

6. Davies RR, Hussain T, Tandon A. Using virtual reality simulated implantation for fit-testing pediatric patients for adult ventricular assist devices. J Thorac Cardiovasc Surg Tech. 2021;6:134-7. 